\title{
Cytotaxonomy of the crickets Endecous Saussure, 1878 with an overview of the chromosomes of Phalangopsinae Group (Orthoptera: Phalangopsinae)
}

\author{
EDISON ZEFA ${ }^{1,4}$, CARMEM SILVIA FONTANETTI $^{2} \&$ LUCIANO DE PINHO MARTINS $^{3}$ \\ ${ }^{1}$ Departamento de Zoologia e Genética, Instituto de Biologia, Universidade Federal de Pelotas (UFPel), 96010-900 Capão do Leão, \\ Rio Grande do Sul, Brazil. E-mail: edzefa@gmail.com \\ ${ }^{2}$ Departamento de Biologia, Instituto de Biociências, São Paulo State University-UNESP. 13506-900 Rio Claro, São Paulo, Brazil. \\ E-mail: fontanet@rc.unesp.br \\ ${ }^{3}$ Coordenação de Pesquisa em Entomologia, Instituto de Pesquisa da Amazônica (INPA), 69060-001, Manaus, Amazonas, Brazil. \\ E-mail: lucianodpm@gmail.com \\ ${ }^{4}$ Corresponding author
}

\begin{abstract}
The karyotypes of five species of crickets Phalangopsinae were studied: E. onthophagus shows $2 \mathrm{n}=19$, X0 0 , pairs 1,7 and 8 metacentric, 2, 3, 6 and 9 submetacentric, 4 and 5 acrocentric; E. itatibensis with $2 \mathrm{n}=19, \mathrm{X} 0 \hat{\mathrm{O}}$, pairs 1,7 and 8 metacentric, 2, 3, 4, 6 and 9 submetacentric, pair 5 acrocentric; E. cavernicolus with $2 \mathrm{n}=21, \mathrm{X} 0 \hat{\mathrm{O}}$, pairs 7,8 and 9 metacentric, pairs 1, 2, 3, 4, 5, 6 and 10 acrocentric; E. betariensis with $2 \mathrm{n}=21$, X0今, pairs 2, 4, 8, 9, and 10 submetacentric, 1, 3, 5, 6 and 7 acrocentric; E. alejomesai with $2 \mathrm{n}=21$, X0 0 , pair 7 metacentric, 1, 2 and 8 submetacentric and 3, 4, 5, 6, 9 and 10 acrocentric. The mechanism of sex determination was $\mathrm{X} 0 \stackrel{1}{\circ}, \mathrm{XX}+$, with $\mathrm{X}$ chromosome metacentric as the largest of the set. We compared and discussed the karyotypes of the species of Endecous with an overview of the chromosomes of Phalangopsinae Group.
\end{abstract}

Key words: Cytogentics, Karyotype, Ensifera, Grylloidea, Luzarinae

\section{Introduction}

The Grylloidea includes about 4500 described species (Eades \& Otte, 2009) and the Phalangopsinae is one of the most important taxons in the Neotropical region (Desutter-Grandcolas, 1995a).

The Phalangopsinae Group includes the subfamilies Cachoplistinae, Luzarinae, Paragryllinae, Phalangopsinae, Phaloriinae and Rumeinae (Eades \& Otte, 2009). The knowledge of karyotypes focuses on Luzarinae, with 21 of the 23 studied species and the chromosome number ranging from $2 \mathrm{n}=11$ to $2 \mathrm{n}=21$. The basic sex determination system is XO, occurring neo-XY in Aracamby (sooretama) ${ }^{1}$ (Mello, 1994) and $\mathrm{X}_{1} \mathrm{X}_{2} \mathrm{Y}$ in Seychellesia Hewitt (1979).

An extensive chromosomal description was published by Mello (1992, 1994), including 11 species of Aracamby with karyotypes ranging from $2 \mathrm{n}=11$ to 17. Mesa \& Melo (1985) and Mesa et al. (1998) shown the chromosomes of three species of Eidmanacris and two of Strinatia, respectively. In Adelosgryllus rubricephalus, Mesa and Zefa (2004) found chromosome variation in two allopatric populations.

The genus Endecous includes 12 described species, seven occurring in the Brazilian territory, and two with information about chromosomes: E. onthophagus (Berg, 1891), with 2n = 19, X0 (Cardoso et al. 1984, Mesa \& Garcia-Novo, 1997) and E. cavernicolus Costa Lima, 1940, with 2n = 19, X0 (Piza, 1945).

The present investigation was carried out in order to compare the karyotype of five species of Endecous, four from the Brazilian territory and E. onthophagus from Uruguay. We also present an overview of the chromosomes of Phalangopsinae Group.

1. Specific name presented in the PhD thesis of Mello (1994), but not published. 